\title{
INSETICIDAS VEGETAIS NO CONTROLE DE Anastrepha spp. (DIPTERA: TEPHRITIDAE) EM POMAR DE GOIABA
}

Artigo submetido em abril de 2013 e aceito em setembro/2013

\section{RESUMO}

Objetivando avaliar os efeitos de inseticidas vegetais sobre Anastrepha spp. em pomar de goiaba, realizaramse pesquisas em Barbalha, de 6 de maio a 24 de junho de 2011, testando Pironat ${ }^{\circledR}$, Rotenat $^{\circledR}$ e Natuneem ${ }^{\circledast}$. Para avaliar o efeito sobre adultos, instalaram-se 20 armadilhas McPhail iscadas com proteína hidrolisada de milho a $5 \%$, quantificando-se o número de insetos capturados. $\mathrm{Na}$ avaliação do efeito sobre larvas, colheram-se ao acaso 100 frutos maduros, verificandose a presença de larvas vivas e mortas. Foram feitas três aplicações em ambos os experimentos com o auxílio de um atomizador costal motorizado, sendo as avaliações realizadas semanalmente. $\mathrm{O}$ extrato pirolenhoso do
Pironat $^{\circledR}$ repele satisfatoriamente adultos de Anastrepha spp., enquanto que a azadiractina presente no Natuneem ${ }^{\circledR}$ promove efeito inseticida sobre as larvas nas condições de campo, sendo estes produtos mais eficazes para o controle da praga a partir da segunda aplicação. Embora estes produtos vegetais não cheguem a causar $100 \%$ de controle, eles podem ser utilizados em programas de Manejo Agroecológico de Anastrepha spp. em pomares de goiaba, pois além de baratos, são de fácil aplicação e não provocam impacto ambiental em termos de risco de resíduos tóxicos nos frutos. Use este espaço para escrever o resumo.

PALAVRAS-CHAVE: Inseticidas botânicos, Moscas das frutas, Psidium guajava

\section{INSECTICIDES VEGETABLES ON THE CONTROL OF ANASTREPHA SPP. (DIPTERA: TEPHRITIDAE) IN GUAVA ORCHARD.}

\begin{abstract}
Aiming to evaluate the effects of vegetables insecticides on Anastrepha spp. in orchard of guava, two researches in Barbalha were conducted, from may $6^{\text {th }}$ to June $24^{\text {th }}$ of 2011, testing Pironat ${ }^{\circledR}$, Rotenat ${ }^{\circledR}$ and Natuneem ${ }^{\circledR}$. To evaluate the effect on adults, $20 \mathrm{McPhail}$ traps baited with protein corn hydrolyzed at $5 \%$ were settled, evaluating the number of insects captured weekly. On the evaluation of the effect on larvae, we collected at random 100 fruits, cheking the presence of larvae alive and dead. Three applications were made of the products in both experiments with a motorized costal atomizer,
\end{abstract}

with evaluations accomplished weekly. The Pyroligneous extract of Pironat ${ }^{\circledast}$ repels the adults of Anastrepha spp satisfactorily, while the azadirachtin present in Natuneem ${ }^{\circledR}$, promotes insecticide effect on the larvae in the field conditions, which these products showed greater efficiency after the second application. Although these vegetable products don't causes $100 \%$ of control, they can be used in agroecological Anastrepha ssp. management in guava orchards, therefore are cheap, of easy application and don't cause environmental impact in terms of risk of toxicant residues in the fruits.

KEYWORDS: Botanical insecticides, fruit flies, Psidium guajava 


\section{INSETICIDAS VEGETAIS NO CONTROLE DE Anastrepha spp. (DIPTERA: TEPHRITIDAE) EM POMAR DE GOIABA}

\section{INTRODUÇÃO}

O cultivo de pomares de goiaba na Região do Cariri cearense tem proporcionado uma alternativa viável para os produtores locais. No entanto, os problemas com o ataque de pragas, como as moscas das frutas do gênero Anastrepha, são os principais entraves para essa cultura (AZEVEDO et al., 2010).

Os danos causados por essas pragas na goiaba são decorrências da oviposição das fêmeas que por meio do ovipositor, perfuram e depositam os ovos no interior do fruto. Muitas vezes, o simples ato da punctura, causa depreciação externa ao fruto. No entanto, o maior prejuízo é causado pelas larvas que se alimentam da polpa dos frutos, tornando-os inviáveis para o consumo humano (MORGANTE, 1991).

A incidência delas em goiabeiras (Psidium guajava L.) é um sério problema nessa região, acarretando aumentos nos custos de produção, devido às aplicações de inseticidas e às perdas na produção. Além disso, os inseticidas usados no controle causam impactos negativos sobre a entomofauna benéfica, além de serem prejudiciais à saúde humana e ao agroecossistema. Anastrepha zenildae, $A$. sororcula, $A$. fraterculus e $A$. obliqua são as espécies que ocorrem nas goiabeira do Cariri cearense (AZEVEDO et al., 2010).

Tradicionalmente, o controle dessas pragas tem sido feito por meio de iscas tóxicas composta de proteína hidrolisada associada ao malathion 1000CE ou triclorfon 500CE, a qual é aplicada em um $1 \mathrm{~m}^{2}$ da copa e em fileiras alternadas, para promover a morte dos adultos por ingestão/contato ou também pelo uso da fentiona 500CE aplicada em cobertura total, com a finalidade de matar ovos, impedir e eliminar a infestação de larvas no fruto (CARVALHO, 2004). Esses princípios ativos registrados para o controle de moscas das frutas (MINISTÉRIO DA AGRICULTURA PECUÁRIA E ABASTECIMENTO, 2009), apresentam carência de 14 a 21 dias, mas este período é considerado muito longo, uma vez que a maior ocorrência da praga se dá nas fases de pré colheita e colheita.

Diante das exigências do mercado consumidor, os produtores têm adotado uma série de medidas alternativas que visam à redução do controle químico. Estas ações conjuntas poderiam levar a uma redução no uso de inseticidas convencionais pelos agricultores, diminuindo desta forma, a contaminação do meio ambiente e aumentando a qualidade dos frutos produzidos e a sua competitividade no mercado.

A possibilidade de cultivo da goiaba sem o uso de inseticidas químicos associadas às exigências por parte dos consumidores tem motivado a conversão de pequenas áreas produtoras para o sistema agroecológico sem redução na produtividade (STORCH et al., 2004). Porém, poucos trabalhos têm sido realizados, visando identificar e analisar a eficiência de estratégias disponíveis para o manejo agroecológico de moscas das frutas. Essas estratégias geralmente são utilizadas de forma empírica, baseada em observações isoladas e, muitas vezes, sem comprovação científica.

Em condições de campo, os trabalhos de manejo de moscas das frutas são difíceis de serem avaliados pela ausência de um padrão de flutuação populacional, sendo esta dependente da existência e da adequabilidade dos hospedeiros (ZUCCHI, 2000), bem como das condições climáticas da região (CHIARADIA et al., 2004).

Com a crescente preocupação ambiental, inúmeras pesquisas têm sido realizadas visando a busca e a utilização de produtos e sistemas de manejo ecologicamente corretos, como por 
exemplo, a utilização de inseticidas vegetais, que venham a contribuir para o controle das moscas das frutas e demais pragas. Neste sentido, a utilização de óleos essenciais e extratos com propriedades inseticidas tornam-se fundamental, sendo conhecidas mais de 2.000 espécies de plantas (VIEGAS JÚNIOR, 2003).

Alguns trabalhos de pesquisa já foram realizados utilizando a azadiractina (VAN RADEN; ROITBERG, 1998; DIILIO et al., 1999; SALLES; RECH, 1999; CIOCIOLA JUNIOR; MARTINEZ, 2002; SINGH, 2003; BARRY et al., 2005; FRANÇA et al., 2010; ANDREAZZA et al., 2011; CHARLOTE, 2011), a rotenona (TADA-OIKAWA et al., 2003; AGUIAR-MENEZES, 2005; EFROM, 2009), assim como, o extrato pirolenhoso (TSUZUKI et al., 2000) para controlar moscas das frutas em goiabeiras e fruteiras em geral.

Assim, visando contribuir para aumentar o conhecimento a respeito do uso dos inseticidas vegetais no controle de Anastrepha spp. na cultura da goiaba, a presente pesquisa foi conduzida com o objetivo de avaliar os efeitos desses inseticidas sobre adultos e larvas dessa praga em condições de campo.

\section{MATERIAL E MÉTODOS}

\section{Área de estudo}

As pesquisas foram conduzidas em um pomar comercial de goiaba (Psidium guajava L.) com dez anos de idade, com frutos da variedade Paluma, na fase de frutificação e maturação dos frutos, localizado a 071' $01,9^{\prime \prime} \mathrm{S}$ de latitude sul e 3920'50"W na longitude oeste, a uma altitude de $445 \mathrm{~m}$ acima do nível do mar, em Barbalha, Ceará. As goiabeiras foram plantadas no espaçamento de $6,0 \times 5,0 \mathrm{~m}$ totalizando 0,5ha de área efetiva. Foram adotadas todas as práticas culturais rotineiras, como adubações, capinas e irrigações, sem haver, no entanto, aplicações de inseticidas químicos para o controle das pragas da goiabeira.

\section{Efeito sobre os adultos}

A pesquisa foi realizada no período de 6 a 27 de maio de 2011, no delineamento experimental em blocos casualizados representado por três inseticidas vegetais, um inseticida químico como testemunha referência e a testemunha absoluta (aplicação com água), com quatro repetições, sendo cada parcela constituída por três plantas. Os tratamentos e dosagens dos produtos utilizados, bem como suas especificações, são apresentados na Tabela 1.

Tabela 1: Especificação dos tratamentos, com os nomes técnicos, nomes comerciais, grupos químicos e dosagens dos produtos utilizados.

\begin{tabular}{cccc}
\hline $\begin{array}{c}\text { Tratamentos } \\
\text { (Nome Técnico) }\end{array}$ & Nome comercial & Grupo Químico & $\begin{array}{c}\text { Dosagem } \\
\mathrm{mL} / \mathrm{L} \text { água }\end{array}$ \\
\hline extrato pirolenhoso & Pironat $^{\circledR}$ & Ácido acético & $1 \mathrm{~mL}$ \\
rotenona & Rotenat $^{\circledR}$ & Rotenóide & $7,5 \mathrm{~mL}$ \\
azadiractina & Natuneem $^{\circledR}$ & Limonóide & $5 \mathrm{~mL}$ \\
fentiona & Lebaycid $^{\circledR} 500 \mathrm{CE}$ & Fosforado & $5 \mathrm{~mL}$ \\
\hline
\end{tabular}

Os inseticidas foram aplicados três vezes a cada sete dias, em cobertura total com um atomizador costal motorizado de $18 \mathrm{~L}$, instalando-se uma armadilha McPhail na planta central de cada parcela para verificar o efeito insetistático e/ou inseticida dos produtos testados. As armadilhas foram iscadas com proteína hidrolisada de milho a $5 \%$, colocando-se em cada armadilha $400 \mathrm{~mL}$ do atrativo alimentar. 
Semanalmente, as armadilhas foram examinadas e as moscas atraídas eram coletadas, utilizando-se uma peneira de malha fina. Os insetos capturados foram acondicionados em recipientes plásticos de $100 \mathrm{~mL}$ contendo álcool a $70 \%$, devidamente etiquetados com os respectivos tratamentos. Em seguida, esse material foi levado ao laboratório de Entomologia da Universidade Federal do Ceará - Campus Cariri, para triagem e contagem das moscas. As armadilhas permaneceram instaladas no pomar durante todo o período de estudo. Apenas o atrativo alimentar era reposto uma vez por semana, durante a coleta das moscas.

Os dados obtidos foram submetidos à análise de variância, comparando-se as médias pelo teste $t$ (LSD) a $5 \%$ de probabilidade. Para efeito de significância, os dados foram transformados em $\sqrt{ } x+0,5$.

\section{Efeito sobre as larvas}

A pesquisa foi conduzida no período de 3 a 24 de junho de 2011, utilizando-se os mesmos produtos nas mesmas dosagens, aplicados três vezes a cada sete dias em cobertura total com o mesmo atomizador costal motorizado da pesquisa anterior.

O delineamento adotado também foi em blocos casualizados, com quatro repetições, sendo cada parcela constituída por três plantas. A avaliação foi realizada, colhendo-se ao acaso cinco frutos maduros da planta central de cada parcela, totalizando 100 frutos em todo 0 experimento. Em seguida, foram levados ao laboratório de Entomologia da UFC Campus Cariri, em sacos plásticos devidamente etiquetados com os respectivos tratamentos, onde foram abertos com uma faca de aço inoxidável no sentido longitudinal e transversal, verificando-se a olho nu a presença de larvas vivas ou mortas no interior dos frutos.

A eficiência dos tratamentos no controle das larvas de Anastrepha spp. foi determinada em porcentagem por meio da fórmula de Abbott (1925): \%E= $(T-t) \times 100 / T$, onde $T=$ testemunha absoluta e $\mathrm{t}=$ tratamentos avaliados.

\section{RESULTADOS E DISCUSSÃO}

\section{Efeito sobre os adultos}

Sete dias após a primeira aplicação, observou-se menor captura de adultos de Anastrepha spp. nas parcelas tratadas com fentiona, seguido do extrato pirolenhoso (Tabela 2), não diferindo estatisticamente entre si. A fentiona como age por contato (ANDREI, 2005), ocasionou uma maior mortalidade aos adultos, reduzindo assim, a captura das moscas nas armadilhas instaladas.

Tabela 2: Número médio de adultos de Anastrepha spp. capturados em armadilhas McPhail submetidos a três aplicações de inseticidas vegetais, Barbalha-CE, 2011.

\begin{tabular}{|c|c|c|c|c|}
\hline Tratamentos & $\begin{array}{c}\text { População } \\
\text { inicial }\end{array}$ & $\begin{array}{c}7 \text { dias da 1a } \\
\text { Aplicação }\end{array}$ & $\begin{array}{l}14 \text { dias da 1a } \\
\text { Aplicação }\end{array}$ & $\begin{array}{c}21 \text { dias da 1a } \\
\text { Aplicação }\end{array}$ \\
\hline Testemunha & 61,00 & $78,25^{1,2} \mathrm{a}$ & $52,75 \mathrm{a}$ & $25,00 \mathrm{a}$ \\
\hline extrato pirolenhoso & 28,75 & $37,00 \mathrm{bc}$ & $17,00 \mathrm{~b}$ & $13,75 a b$ \\
\hline rotenona & 33,75 & $47,00 \mathrm{~b}$ & $43,75 \mathrm{ab}$ & $20,50 a$ \\
\hline azadiractina & 42,25 & $50,00 a b$ & $27,00 a b$ & $27,25 \mathrm{a}$ \\
\hline fentiona & 20,00 & $21,75 c$ & $12,00 \mathrm{~b}$ & $8,50 \mathrm{~b}$ \\
\hline C.V. (\%) & & 19,41 & 37,12 & 25,59 \\
\hline Total & 185,75 & 234,00 & 152,50 & 95,00 \\
\hline
\end{tabular}


De acordo com Tsuzuki et al. (2000), em condições naturais, o efeito do extrato pirolenhoso se dá devido a ativação de substâncias do metabolismo secundário das plantas, induzindo desta maneira a resistência ao ataque dos insetos. Essa resistência ocorre por conter no extrato ácido acético, guaiacol, metilguaiacol, siringol, metilsiringol, fenol, cresol, etc (NATURAL RURAL, 2011). Portanto, acredita-se que as plantas da goiabeira devido à aplicação desse extrato tornaram-se menos preferida para oviposição. Pansiera et al. (2003) constataram que ao aplicarem extrato pirolenhoso de Eucalyptus grandis em folhas de tomateiro, conseguiram reduzir significativamente a oviposição de Tuta absoluta.

Já naquelas parcelas tratadas com rotenona e azadiractina, houve maior captura entre os inseticidas vegetais testados e, portanto, menor efeito sobre os adultos nesse período de avaliação (sete dias), diferindo, por conseguinte, da testemunha absoluta que capturou 78,25 adultos (Tabela 2).

A rotenona quando aplicada em pulverizações sobre a superfície das plantas promove proteção por aproximadamente uma semana (AGUIAR-MENEZES, 2005). Provavelmente, nesse período de avaliação esse princípio ativo não tenha desempenhado a sua ação inseticida ou então a dosagem foi baixa para as condições em que a pesquisa foi realizada.

Em condições de laboratório, Viana et al. (2009) verificaram que a rotenona, na dosagem de 1,5mL/500mL de água aplicado diretamente sobre adultos de Ceratitis capitata após 2, 4 e $6 \mathrm{~h}$ de aplicação, não apresenta eficiência no controle dessa praga, nem por contato nem por ingestão.

Com relação à azadiractina, resultados de pesquisas nas mesmas condições de laboratório comprovaram os efeitos prejudiciais em adultos de moscas das frutas quando estas se alimentaram com compostos à base de nim (DIILIO et al., 1999; SALES; RECH, 1999; SINGH, 2003).

Talvez em condições de campo devido às altas temperaturas do Estado do Ceará, no Nordeste brasileiro e, só com uma aplicação, esses produtos não desempenhem efeito sobre os insetos adultos. Corroborando com os resultados dessa pesquisa, Barry et al. (2005), ao avaliarem, em condições de laboratório e campo, o efeito dos produtos à base de azadiractina (Aza-Direct ${ }^{\circledR}$ e $^{\text {Agroneem }}{ }^{\circledR}$ ) sobre Rhagoletis mendax Curran, verificaram que em laboratório, os produtos causaram baixa mortalidade tópica, nenhum efeito após exposição residual e nenhuma repelência. Em campo os autores não observaram diferença significativa no número de adultos capturados, mas a quantidade de larvas nos frutos tratados foi significativamente menor que a testemunha.

Nesse período de avaliação nenhum inseticida promoveu redução da população inicial. A mesma praticamente permaneceu a mesma e isso provavelmente ocorreu devido a uma forte pressão de ataque das moscas sobre os frutos, pois no pomar a população mantinha-se em uma média de 234 indivíduos (Tabela 2).

Quatorze dias após a primeira aplicação, constatou-se novamente menor captura de adultos nas parcelas tratadas com fentiona, ocorrendo o mesmo naquelas tratadas com o extrato pirolenhoso, não diferindo estatisticamente entre si, no entanto, difeririam da testemunha absoluta, com 52,75 adultos e da azadiractina e do extrato pirolenhoso, com capturas de 27 e 43,75 adultos, respectivamente (Tabela 2).

A fentiona promoveu uma mortalidade de $44,83 \%$ da população do período anterior, onde esta estava com uma média de 21,75 adultos, enquanto que o extrato pirolenhoso promoveu uma repelência de $54 \%$ dessa população, estando com uma média de 37 adultos, eficiência essa, superior a do inseticida químico (Tabela 2). 
Nesse período de avaliação (14 dias) a azadiractina também repeliu $46 \%$ da população anterior, ou seja, também próximo da eficiência do extrato e da fentiona. Acredita-se então que o óleo de nim desempenha um melhor efeito repelente a partir da segunda aplicação do produto na dosagem de $5 \mathrm{~mL} / \mathrm{L}$ de água, na concentração de $1 \%$ do ingrediente ativo. Andreazza et al. (2011) verificaram em condições de laboratório que ao aumentarem a concentração do óleo de nim de 0,25 para $1 \%$ houve uma forte tendência de aumento na repelência de adultos de $C$. capitata, também já constatado por Charlote (2011).

Já a rotenona não diferiu da testemunha absoluta, não havendo praticamente nenhuma redução na captura de adultos nesse período de aplicação. A rotenona apresenta, segundo Aguiar-Menezes (2005), amplo espectro de ação por contato e ingestão, mas decompõe-se rapidamente pela ação da luz e calor, apresentando em média uma semana ou menos de efeito residual. Provavelmente, esse produto deveria ser aplicado em intervalos menores, para promover melhor controle da praga nas condições de campo.

Nesse período, houve uma redução da população total, mas ainda permaneceu com uma forte pressão de ataque sobre os frutos, chegando a alcançar uma média de 152,5 indivíduos (Tabela 2).

Vinte e um dias após a primeira aplicação, observou-se novamente que a fentiona e o extrato pirolenhoso capturaram menos adultos e, portanto, foram mais eficientes no controle das moscas, não diferindo estatisticamente entre si. No entanto, a fentiona promoveu apenas $29,17 \%$ de mortalidade aos insetos adultos e o extrato pirolenhoso $19,12 \%$ de repelência.

A rotenona e a azadiractina não diferiram estatisticamente da testemunha absoluta com relação à captura dos adultos, com uma média acima de 20 indivíduos, não havendo redução da população do período anterior pela azadiractina, porém a rotenona chegou a reduzir $53,14 \%$ da população anterior (Tabela 2). Esse inseticida vegetal apresentou um aumento significativo de sua eficiência nesse período de aplicação (21 dias). Provavelmente, isso tenha ocorrido em virtude de uma maior concentração da rotenona na planta ao longo das três aplicações do produto, promovendo um maior controle devido ao efeito cumulativo do produto, já que nas duas primeiras aplicações, observou-se uma menor eficiência.

Os inseticidas vegetais de uma maneira geral apresentam rápida degradação no ambiente, podendo ser exigidas muitas aplicações para se obter o controle satisfatório. Provavelmente nesse período de aplicação o extrato pirolenhoso e a azadiractina perderam a sua capacidade inseticida e/ou insetistática devido a um maior tempo de exposição aos raios solares sobre as moléculas que por não serem sintéticas são instáveis no meio ambiente, com baixo poder residual.

Observou-se nessa pesquisa que o período de menor captura e, portanto, maior efeito dos inseticidas sobre a população dos adultos da praga ocorre a partir da segunda aplicação, pois se observou uma média na redução da captura da população em torno de $38 \%$, entre os produtos testados, quando comparado com a primeira que não houve redução e com a terceira que teve uma média de $20,58 \%$ de redução da população (Tabela 2).

\section{Efeito sobre as larvas}

Sete dias após a primeira aplicação, observou-se uma mortalidade de $75 \%$ das larvas de Anastrepha spp. quando aplicou-se a azadiractina nos frutos da goiabeira. Já a rotenona causou $43,75 \%$, enquanto que o extrato pirolenho somente $25 \%$ de mortalidade (Tabela 3). A azadiractina, segundo Ciociola Junior e Martinez (2002), é mais efetiva por ingestão do que por contato e como as larvas das moscas das frutas são mastigadoras, acredita-se que teve uma 
maior atuação sobre elas, causando uma maior mortalidade quando comparado com os outros inseticidas vegetais nesse período de aplicação.

Tabela 3: Porcentagem média de mortalidade de larvas de Anastrepha spp. em frutos de goiaba submetidos a três aplicações de inseticidas vegetais, Barbalha-CE, 2011.

\begin{tabular}{lcccc}
\hline \multicolumn{1}{c}{ Tratamentos } & $\begin{array}{c}\text { 7 dias da 1a } \\
\text { Aplicação }\end{array}$ & $\begin{array}{c}\text { 14 dias da 1a } \\
\text { Aplicação }\end{array}$ & $\begin{array}{c}\text { 21 dias da 1a } \\
\text { Aplicação }\end{array}$ & Total \\
\hline extrato pirolenhoso & 25,00 & 37,04 & 82,14 & 48,06 \\
rotenona & 43,75 & 14,81 & 57,14 & 38,57 \\
azadiractina & 75,00 & 70,37 & 78,57 & 74,65 \\
fentiona & 100,00 & 81,48 & 92,86 & 91,45 \\
\hline
\end{tabular}

A azadiractina atua interferindo no funcionamento das glândulas endócrinas que controlam a metamorfose em insetos, impedindo o desenvolvimento na fase larval, devido à interferência na regulação neuroendócrina de hormônios nas larvas (VIEGAS JÚNIOR, 2005).

Corroborando com essa afirmativa, França et al. (2010) ao avaliar o efeito do óleo de nim nas concentrações de 0,5\%,1\% e 1,5\%, sobre larvas de Ceratitis capitata, perceberam que o óleo não apresenta efeito prejudicial por contato, não afetando a emergência de adultos.

Já a rotenona promove a redução dos batimentos cardíacos, depressão de movimentos respiratórios e redução no consumo de oxigênio das larvas (GALLO et al., 2002), pois é um potente inibidor da respiração celular bloqueando a cadeia de transporte de elétrons nas mitocôndrias por ligar-se a enzima NADH:Q oxido-redutase (Complexo I) e impedindo a oxidação do $\mathrm{NADH}_{2}$ (TADA-OIKAWA et al., 2003). Como age em um curto espaço de tempo, provavelmente não apresentou uma boa ação de profundidade que pudesse alcançar satisfatoriamente as larvas dentro do fruto de goiaba.

O extrato pirolenho como age como um indutor de resistência, provavelmente teve maior dificuldade de penetração nos frutos nesse período de aplicação, não chegando a causar uma mortalidade satisfatória nas larvas presentes no interior dos frutos avaliados.

Quatorze dias após a primeira aplicação, somente a azadiractina foi eficiente no controle das larvas, causando uma mortalidade de $70 \%$. Valor esse, bem próximo da fentiona, com $81,48 \%$ de mortalidade (Tabela 3), considerado inseticida referência no controle dessa praga.

Vinte e um dias após a primeira aplicação, observou-se que a azadiractina manteve a sua porcentagem de mortalidade acima de $70 \%$ ao longo das três aplicações dos inseticidas, valor esse considerado ótimo em programas de manejo de pragas e também bem próximo da porcentagem de mortalidade causada pelo produto químico.

O extrato pirolenhoso promoveu mortalidade similar a azadiractina, apresentando um aumento significativo de sua eficiência nesse período de aplicação, atingindo uma média de mortalidade acima de $80 \%$ das larvas das moscas das frutas. Provavelmente, isso tenha ocorrido em virtude de uma maior concentração do extrato nos frutos ao longo das três aplicações, promovendo um maior controle devido ao efeito cumulativo do produto, já que na primeira e segunda aplicação, esse inseticida promoveu apenas 25 e 37,04\% de mortalidade. Sendo assim, acredita-se que o extrato pirolenhoso do Pironat ${ }^{\circledR}$ após penetrar nos frutos com uma maior concentração funcionou como um ativador fisiológico da planta promovendo uma resistência induzida tornando-a mais resistente ao ataque da praga e, provavelmente induziu a uma antibiose que ocasionou mortalidade nas larvas. 
A rotenona também demonstrou uma boa eficiência de controle sobre as larvas entre os produtos testados, pois alcançou $57,14 \%$ de mortalidade, nesse período de aplicação, valor esse também considerado satisfatório.

Levando-se em conta o total das três aplicações, percebe-se que dentre os inseticidas vegetais avaliados, a azadiractina se destaca, causando uma mortalidade acima de $70 \%$. Acreditase que a maior eficiência no controle exercido pelo óleo de nim se deva a sua maior persistência, conferida pela sua formulação à base de óleo, que permite que haja uma maior aderência do produto às folhas e frutos da goiabeira quando comparado aos demais produtos testados.

Com relação aos custos de aplicação, percebe-se que os produtos a base de inseticidas vegetais são mais baratos que o químico (Tabela 4). Mesmo utilizando-se dois produtos onde um age sobre os adultos (Pironat ${ }^{\circledR}$ ) e o outro sobre as larvas (Natuneem ${ }^{\circledR}$ ), o agricultor ainda terá uma grande economia nos custos por hectare, pois gastará em média $\mathrm{R} \$ 173,00$ por hectare, valor mais baixo do que o químico que custa $\mathrm{R} \$ 300,00$.

Tabela 4: Valores em reais e custo de aplicação por hectare em pomar de goiaba dos produtos a base de inseticidas vegetais, comparado com o químico.

\begin{tabular}{lccc}
\hline \multicolumn{1}{c}{ Produtos } & Valor unitário (R\$) & Litros/ha & Custo da aplicação (R\$) \\
\hline Pironat $^{\circledR}$ & 8,00 & 1 & 8,00 \\
Rotenat $^{\circledR}$ & 28,00 & 4,5 & 126,00 \\
Natuneem $^{\circledR}$ & 55,00 & 3 & 165,00 \\
Lebaycid $^{\circledR} 500 \mathrm{CE}$ & 100,00 & 3 & 300,00 \\
\hline
\end{tabular}

Por serem produtos naturais degradam facilmente, sobretudo em condições de alta luminosidade, umidade e chuva. Ou seja, esses produtos possuem menor persistência no ambiente, reduzindo o seu impacto a organismos benéficos, homem e ambiente (MOREIRA et al., 2005), não deixando resíduos como ocorre com os inseticidas químicos principalmente aqueles com grande poder residual.

Considerando os resultados obtidos pode-se concluir que o extrato pirolenhoso presente no Pironat ${ }^{\circledR}$ repele adultos de Anastrepha spp. em condições de um pomar comercial de goiaba. A azadiractina presente no Natuneem ${ }^{\circledR}$ promove maior efeito inseticida sobre as larvas de Anastrepha spp. nessas condições. Os inseticidas vegetais são mais eficazes para o controle de Anastrepha spp. a partir da segunda aplicação dos produtos e embora os produtos testados não causem $100 \%$ de controle, eles podem ser utilizados em programas de Manejo Agroecológico de Anastrepha spp. em pomares de goiaba, pois além de baratos, são de fácil aplicação e não provocam impacto ambiental em termos de risco de resíduos tóxicos nos frutos de goiaba.

\section{Agradecimentos}

Ao agricultor Sr. Antônio José Leite pela disponibilidade da área para instalação dos experimentos. Ao professor José Valmir Feitosa pelo apoio nas análises estatísticas. Ao Banco do Nordeste (ETENE/FUNDECI), pelo financiamento da pesquisa.

\section{REFERÊNCIAS BOBLIOGRÁFICA}

1. ABBOTT, W. S. A method of computing the effectiveness of an insecticide. Journal of Economic Entomology, Knoxville, v. 18, p. 265-267, 1925.

2. AGUIAR-MENEZES, E. L. Inseticidas botânicos: seus princípios ativos, modo de ação e uso agrícola. Seropédica: Embrapa Agrobiologia, 2005. 58 p. 
3. ANDREAZZA, F.; GONÇALVES, R. S.; LISBÔA, H.; NAVA, D. E.; CUNHA, U. S. Efeito de nim sobre Ceratitis capitata (Wied.) (Diptera: Tephritidae) via isca tóxica em laboratório. In: CONGRESSO DE INICIAÇÃO CIENTíFICA, 20, 2011, Pelotas. Resumos..., Pelotas: UFPEL, 2011. Versão eletrônica.

4. ANDREI, E. Compêndio de defensivos agrícolas. São Paulo: Andrei, 2005. 1141 p.

5. AZEVEDO, F. R.; GUIMARÃES, J. A.; SIMPLícIO, A. A. F.; SANTOS, H. R. Análise faunística e flutuação populacional de moscas-dasfrutas (Diptera: Tephritidae) em pomares comerciais de goiaba na região do cariri cearense. Arquivos do Instituto Biológico, São Paulo, v. 77, n. 1, p. 33-41, 2010.

6. BARRY, J. D.; SCIARAPPA, W. J.; TEIXEIRA, L. A. F. Comparative effectiveness of different insecticides for organic management of blueberry maggot (Diptera: Tephritidae). Journal of Economic Entomology, Knoxville, n. 98, p. 1236-1241, 2005.

7. CARVALHO, R. S. Monitoramento de parasitóides nativos e de tefritídeos antes da liberação de Diachasmimorpha longicaudata (Hymenoptera: Braconidae) no submédio São Francisco. Cruz das Almas: Embrapa, 2004. 6 p. (Boletim Técnico, 100).

8. CHARLOTTE, C. S. Ação do óleo de nim (Azadirachta indica) sobre Ceratitis capitata (Diptera: Tephritidae) e Diachasmimorpha longicaudata (Hymenoptera: Braconidae). 2011. 54 f. Dissertação (Mestrado em Entomologia e Conservação da Biodiversidade) Universidade Federal da Grande Dourados, Dourados. 2011.

9. CHIARADIA, L.A.; MILANEZ, J. M.; DITTRICH, R. Flutuação populacional de moscas das frutas em pomares de citros no oeste de Santa Catarina. Ciência Rural, Santa Maria, v. 34, n. 2, p. 337-343, 2004.

10. CIOCIOLA JUNIOR, A. I.; MARTINEZ, S. S. Nim: alternativa no controle de pragas e doenças. Belo Horizonte: EPAMIG, 2002. 24 p. (Boletim Técnico, 67).

11. DIILIO, V.; CRISTOFARO, M.; MARCHINI, D.; NOBILI, P.; DALLAI, R. Effects of a neem compound on the fecundity and longevity of Ceratitis capitata (Diptera: Tephritidae). Journal of Economic Entomology, Knoxville, v. 92, n. 1, p. 76-82, 1999.

12. EFROM, C. F. S. Criação de Anastrepha fraterculus (Wied) (Diptera: Tephritidae) em dieta artificial e avaliação de produtos fitossanitários utilizados no sistema orgânico de produção sobre esta espécie e insetos benéficos. 2009. 89 f. Tese (Doutorado em Fitotecnia) - Universidade Federal do Rio Grande do Sul, Porto Alegre. 2009.

13. FRANÇA, W. M.; ALVARENGA, C. D.; GIUSTOLIN, T. A.; OlIVEIRA, P. R.; CRUZ, P. L.; LOPES, G. N.; PARANHOS, B. A. J. Efeito do nim (Azadirachta indica) na mosca-das-frutas Ceratitis capitata (Diptera: Tephritidae) e seu parasitoide Diachasmimorpha longicaudata (Hymenoptera: Braconidae). Arquivos do Instituto Biológico, São Paulo, v. 77, n. 1, p. 5764, 2010.

14. GALLO, D.; NAKANO, O.; SILVEIRA NETO, S.; CARVALHO, R. P. L.; BAPTISTA, G. C. de.; BERTI FILHO, E.; PARRA, J. R. P.; ZUCCHI, R. A.; ALVES, S. B.; VENDRAMIM, J. D.; MARCHINI, L. C.; LOPES, J. R. S.; OMOTO, C. Entomologia agrícola. Piracicaba: FEALQ, 2002. 920 p.

15. MOREIRA, M. D.; PICANÇO, M. C.; SILVA, É. M.; MORENO, S. C.; MARTINS, J. C. Uso de inseticidas botânicos no controle de pragas. In: VENZON, M.; PAULA JÚNIOR T. J.; PALLINI, 
A. (Eds). Controle alternativo de pragas e doenças. Viçosa: EPAMIG/CTZM, 2005, p. 89120.

16. MINISTÉRIO DA AGRICULTURA PECUÁRIA E ABASTECIMENTO. 2009. Disponível em $<$ http://agrofit.agricultura.gov.br> Acesso em: 12 de julho 2009.

17. MORGANTE, J. S. Moscas-das-frutas. Tephritidae: características biológicas, detecção e controle. Brasília: SENIR, 1991. 19 p. (Boletim Técnico, 2).

18. NATURAL RURAL. 2011. Disponível em <http://www.naturalrural.com.br>. Acesso em: 11 agosto 2011.

19. 17. PANSIERA, V. C.; BOGORNI, P. C.; VENDRAMIM, J. D.; GONÇALVES-GERVASIO, R. C. R.; BRITO, J. O. Efeito do ácido pirolenhoso de Eucalyptus grandis sobre a oviposição de Spodoptera Frugiperda (J.E. Smith) e Tuta absoluta (Meyrick). In: SIMPÓSIO DE CONTROLE BIOLÓGICO, 8, 2003, São Pedro. Resumos... São Pedro: SEB, 2003. Versão eletrônica.

20. 18. SALLES, L. A. B.; RECH, N. L. Efeitos de extratos de nim (Azadiractha indica) e cinamomo (Melia azedarach) sobre Anastrepha fraterculus (Wied.) (Diptera: Tephritidae). Revista Brasileira de Agrociência, Pelotas, v. 5, n. 3, p. 225-227, 1999.

21. 19. SINGH, S. Effects of aqueous extract of neem seed kernel and azadirachtin on the fecundity, fertility and post-embryonic development of the melonfly, Bactrocera cucurbitae and the oriental fruit fly, Bactrocera dorsalis (Diptera: Tephritidae). Journal of Applied Entomology, Goettingen, v. 127, p. 540-547, 2003.

22. 20. STORCH, G.; SILVA, F. F.; BRIZOLA, R. M. O.; AZEVEDO, R.; VAZ, D. S.; BEZERRA, A. J. A. Caracterização de um grupo de produtores agroecológicos do sul do Rio Grande do Sul. Revista Brasileira de Agrociência, Pelotas, v. 10, n. 3, p. 357- 362, 2004.

23. 21. TADA-OIKAWA, S.; HIRAKU, Y.; KAWANISHI, M.; KAWANISHI, S. Mechanism for generation of hydrogen peroxide and change of mitochondrial membrane potential during rotenone-induced apoptosis. Life Sciences, Tucson, n. 73, p. 3277-3288, 2003.

24. 22. TSUZUKI, E.; MORIMITSU, T.; MATSUI, T. Effect of chemical compounds in rice plant. Japan Journal Crop Science, Nagoya, v. 66, n. 4, p. 15-16, 2000.

25. 23. VAN RANDEN, E. J.; ROITBERG, B. D. Effect of a neem (Azidirachta indica)-based insecticide on oviposition deterrence, survival, behavior, and reproduction of adult western cherry fruit fly (Diptera: Tephritidae). Journal of Economic Entomology, Knoxville, v. 91, n. 1, p. 123-131, 1998.

26. 24. VIANA, R. E.; VIRGÍNIO, J. F.; DAMASCENO, I. C.; PARANHOS, B. J. Eficiência de inseticidas no controle de Ceratitis capitata (Diptera: Tephritidae). In: SEMINÁRIO BRASILEIRO DE PRODUÇÃO INTEGRADA DE FRUTAS, 11, 2009, Petrolina. Resumos... Petrolina: Embrapa Semiárido, 2009. Versão eletrônica.

27. 25. VIEGAS JÚNIOR, C. Terpenos com atividade inseticida: uma alternativa para o controle químico de insetos. Química Nova, São Paulo, v. 26, p. 390-400, 2003.

28. 26. ZUCCHI, R. A. Lista das espécies de Anastrepha, sinonímias, plantas hospedeiras e parasitóides. In: MALAVASI, A.; ZUCCHI, R. A. (Eds). Moscas-das-frutas de importância econômica no Brasil, conhecimento básico e aplicado. Ribeirão Preto: Holos Editora, 2000. p. 41-48. 